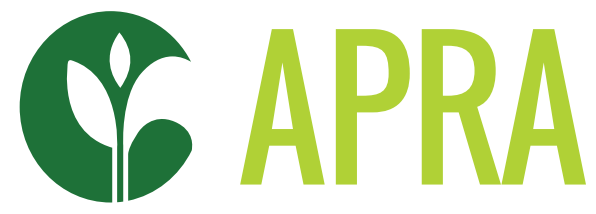

Agricultural Policy Research in Africa

\title{
THE EMERGING IMPORTANCE OF RICE AS A STRATEGIC CROP IN ETHIOPIA
}

Dawit Alemu and John Thompson 


\section{CONTENTS}

Acronyms 4

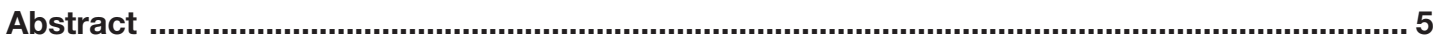

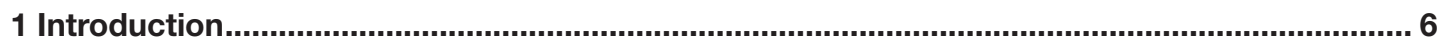

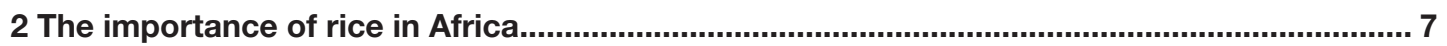

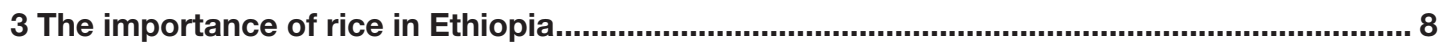

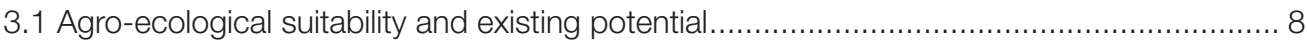

3.2 Compatibility of rice in the local farming systems and food recipes .............................. 9

3.3 The economic incentives of rice production ............................................................ 11

3.4 Rice imports and the burden on foreign currency................................................. 11

3.5 Public policy environment and support of development partners................................ 11

4 Trends in rice production, imports and domestic consumption ............................................ 13

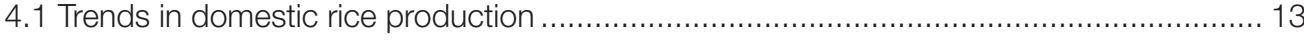

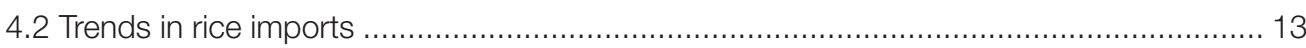

4.3 Trends in domestic consumption and self-sufficiency ........................................... 14

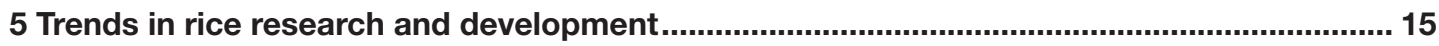

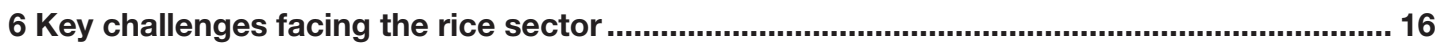

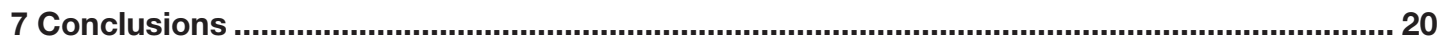

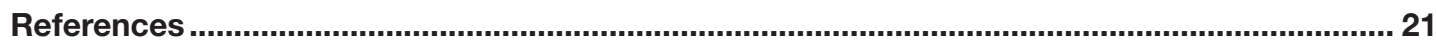

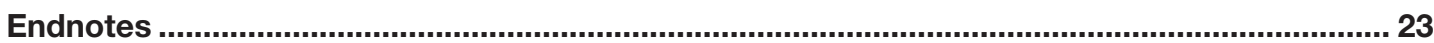

Figures

Figure 2.1 Rice self-sufficiency for selected SSA countries ............................................ 7

Figure 3.1 Suitability map for rice production under rain-fed conditions .............................. 8

Figure 3.2 Distribution of the national rice hubs in Ethiopia, 2018 ….................................. 9

Figure 4.1 Trends in rice production, imports, consumption and level of self-sufficiency (2008-2019)

Figure 6.1 Expected vulnerability of CARD member countries during

COVID-19 pandemic 18 


\section{ACKNOWLEDGEMENTS}

Dawit Alemu is agricultural economist serving as a manager of BENEFIT Partnership program in Ethiopia. He is a member the Future Agricultures Consortium (FAC) and country lead of the Agricultural Policy Research in Africa (APRA) Programme in Ethiopia.

John Thompson is a Senior Research Fellow at the Institute of Development Studies (IDS), UK. He serves as the Director of the Future Agricultures Consortium (FAC) and CEO of the Agricultural Policy Research in Africa (APRA) Programme.

This research was conducted with funding from UK aid of the UK government (Foreign, Commonwealth \& Development Office - FCDO, formerly DFID). The opinions are the authors' and do not necessarily reflect the views or policies of the UK government or FCDO. 


\section{ACRONYMS}

\begin{tabular}{ll} 
AgroBIG & Agro-business induced growth \\
ATA & Agricultural Transformation Agency \\
CARD & Coalition for African Rice Development \\
CSA & Central Statistical Agency of Ethiopia \\
EIAR & Ethiopian Institute of Agricultural Research \\
ERCA & Ethiopian Revenue and Customs Authority \\
IRRI & International Rice Research Institute \\
JICA & Japan International Cooperation Agency \\
MEDA & Mennonite Economic Development Associates \\
MoANR & Ministry of Agriculture and Natural Resources \\
NCERR & National Center of Excellence for Rice Research and Capacity Building \\
NRRDS & National Rice Research and Development Strategy \\
NRRTC & National Rice Research and Training Center \\
NSC & National Steering Committee \\
NTC & National Technical Committee \\
PPP & public-private partnership \\
R\&D & research and development \\
RSSDS & Rice Seed Sector Development Strategy \\
SSA & sub-Saharan Africa \\
\hline
\end{tabular}




\section{EXECUTIVE SUMMMARY}

In line with its increased importance throughout Africa, rice has become one of the most important agricultural commodities in Ethiopia. Through the use of secondary data, this document examines the trends of the importance of rice - covering the domestic production, imports, the extent of self-sufficiency and associated efforts.

The results indicate that the country is endowed with huge production potential that could be exploited through strategic interventions from the federal government in collaboration with several international initiatives led by AfricaRice, the Coalition for African Rice Development (CARD), EthioRice, and the International Rice Research Institute (IRRI). However, the rapid rise of rice imports from Asia has been much higher than the rate of increase in domestic production; resulting in a continuing decline in the level of self-sufficiency. It is estimated that the self-sufficiency level has fallen from approximately 70 per cent in 2008 to 24 per cent in 2019; creating a burden on the meagre foreign currency reserves.

In general, the main challenges facing rice sector development in Ethiopia are related to (i) poor performance of the rice seed sector and other inputs, (ii) limited contribution of commercial rice production (though there is special incentive for access to land), (iii) competition of imported rice with local production in terms of both quality and quantity, (iv) lack of skilled human resources and research facilities, (v) poor infrastructure for improving rice production and (vi) an underdeveloped marketing system for domestic rice compared to imported rice. The recent COVID-19 outbreak and resultant preventive lockdowns in early 2020 have posed new challenges, with rice supply chains disrupted across the country and the wider region. Closure of frontiers and temporary trade restrictions on major Asian rice exporters led to increases in rice prices in international markets. Rice futures prices rose to levels not seen for nearly a decade. This price shock and supply squeeze threatens to further aggravate an already fragile food security situation in the country and highlights the need for greater efforts at rice self-sufficiency on a national scale. However, we can already identify several important opportunities to respond to these challenges; including growing policy commitment to rice sector development, the possibility of drawing lessons from other countries (especially in Asia) to adapt available technologies and practices along the entire rice value chain and increased commitment of development partners to mobilise research and development investments to support state efforts in transforming the rice sector in the country.

Keywords: rice, COVID-19, domestic production, food security, imports, international trade, self-sufficiency, Ethiopia 


\section{INTRODUCTION}

Rice is one of the major staple crops globally and is the most rapidly growing food commodity in sub-Saharan Africa (SSA). The region consumes 30 per cent of the world's production of rice while representing only 10 per cent of its total population (Seck et al. 2013). This trend has resulted in a low level of self-sufficiency in rice - estimated at 60 per cent - while costing a considerable amount of foreign currency to maintain imports (Wopereis et al. 2013). The same trends have been observed in Ethiopia, where there is an increasing reliance on imported rice to meet rapidly growing demand.

Rice is a relatively recent introduction to Ethiopia; a fact linked with the quest to address the various challenges of different public interventions during the Derge regime. These challenges were mainly related to settlement and food security. The first areas of rice introduction were Gambella (1973-1982), Pawe (1985-1988) and Fogera Plain (early 1980s). However, of these areas, only Fogera Plain remained one of the major rice production areas; experiencing the hugely significant changes in agrarian relations and social dynamics associated with the introduction of rice and its subsequent commercialisation.

This paper presents the challenges and opportunities surrounding rice cultivation, processing and marketing in Ethiopia. Specifically, it deals with (i) the growing importance of rice in the country, (ii) the trends in rice production, imports and domestic consumption, (iii) the general research and development efforts made to catalyse more opportunities rice can offer to the country and (iv) the key challenges and opportunities for the future development of the rice sector in Ethiopia. 


\section{THE IMPORTANCE OF RICE IN AFRICA}

Demand is growing rapidly for rice in Africa because of three main factors. These are (i) rapid population growth, (ii) increasing per capita consumption and (iii) consumer preferences shifting towards premium rice as a result of increased urbanisation. African rice consumption is projected to reach nearly $35 \mathrm{Mt}$ of milled rice by 2025 , of which $12.6 \mathrm{Mt}$ will be imported at a cost of approximately US\$5.5 billion annually (AfricaRice 2018a). Today, African rice production is unable to satisfy demand either in terms of quantity or quality. Even major rice-producing countries such as Côte d'Ivoire, Guinea, Madagascar, Mali, Nigeria and Tanzania, are unable to achieve self-sufficiency (Figure 2.1). If current trends continue, by 2025 African rice production will meet less than two-thirds of the continent's demand. The remaining one-third will have to be met by imports of predominantly Asian rice (AfricaRice 2018a).
A transformation of the rice value chain across Africa will require mobilising upwards of US\$26 billion over the next decade (AfricaRice 2018b). Approximately 80 per cent of the required investment will go towards increasing production through access to improved inputs and production practices; including quality seeds, irrigation and small-scale agricultural machinery. The remaining 20 per cent will be invested in improving rice quality through improved processing efficiency and storage; including milling facilities, warehouses and logistics (AfricaRice 2018b).

Figure 2.1 Rice self-sufficiency for selected SSA countries

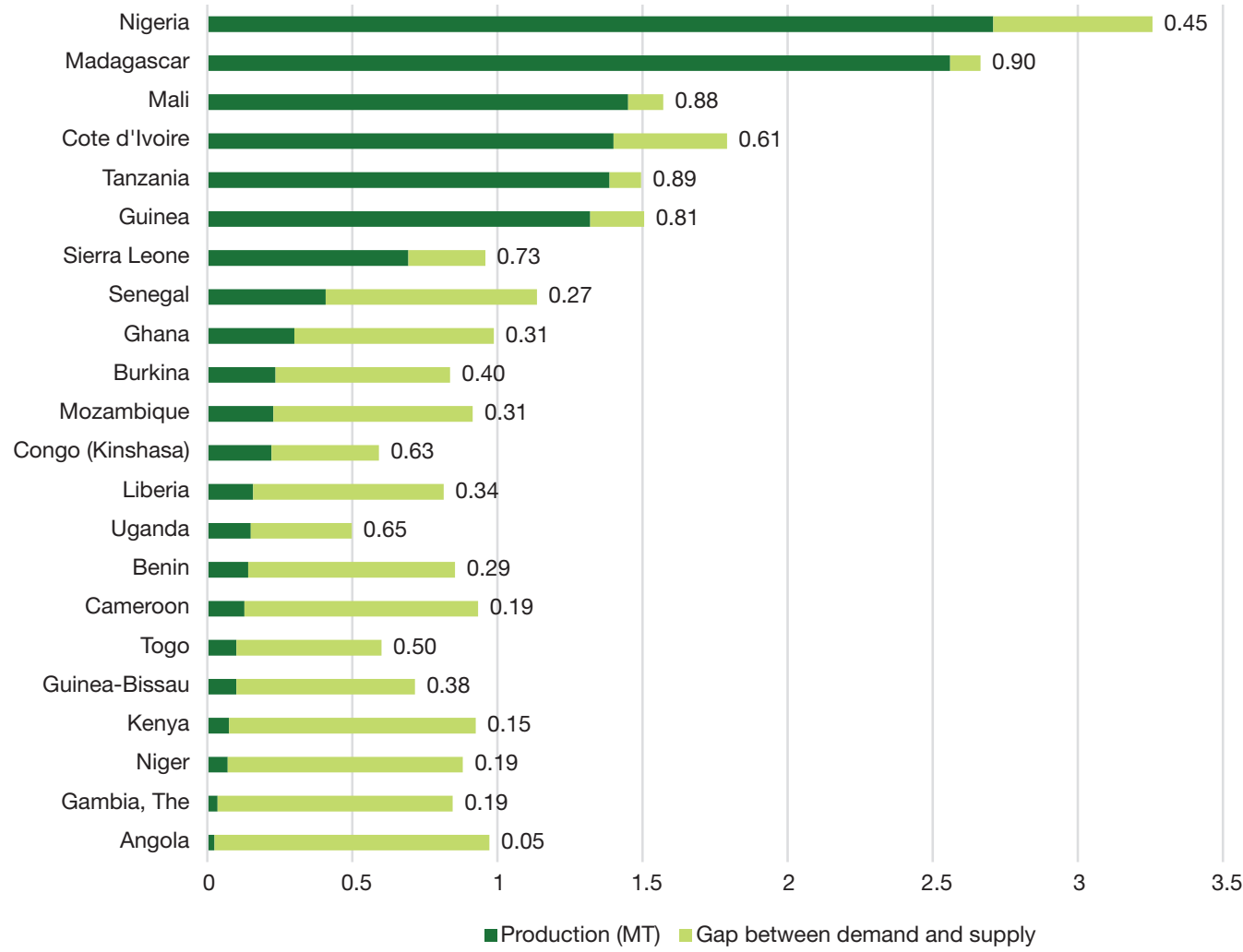

Source: AfricaRice 2018a 


\section{THE IMPORTANCE OF RICE IN ETHIOPIA}

Several factors have influenced the emergence of rice as an important food security crop and strategic commodity in Ethiopia over the past three decades. These are related to (i) the trend in the expansion of rice production linked with agro-ecological suitability and existing potential, (ii) the compatibility of rice in local farming systems and traditional foods, (iii) the economic incentives of rice production (comparative advantage), (iv) the rapid increase in domestic rice consumption and the associated burden on foreign currency due to rice imports and (v) the favourable public policy environment and support of development partners. These factors are discussed in more detail below.

\subsection{Agro-ecologicall suitability and existing potential}

It is estimated that the country is endowed with about 30 million ha of land, of which 5.6 million ha are categorised as highly suitable and another 25 million ha as suitable for rain-fed rice production. In addition,

Figure 3.1 Suitability map for rice production under rain-fed conditions

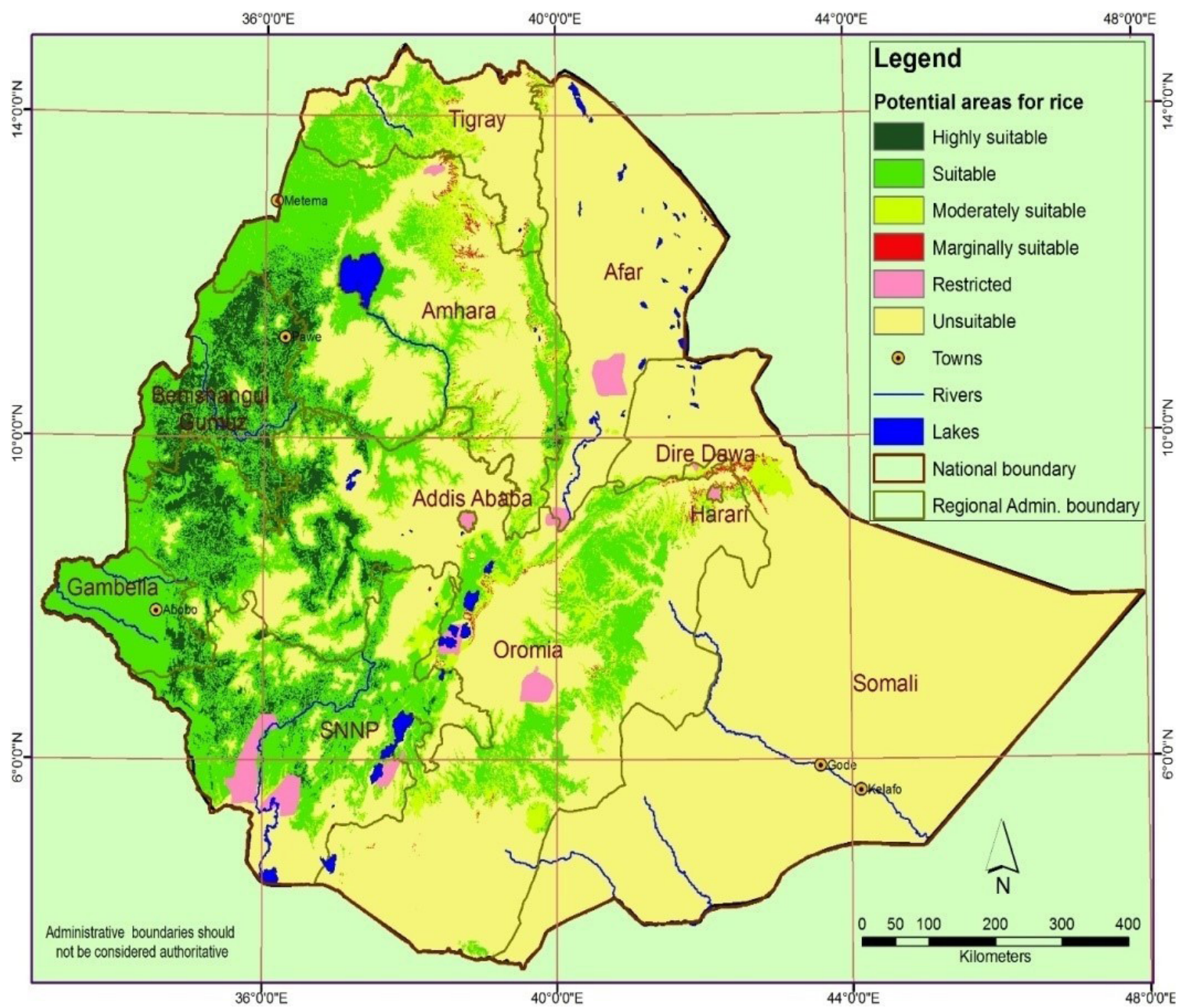

Source: MoANR (2010) 
about 3.7 million ha are deemed as suitable for irrigated rice production. These are distributed around the ten river basins in the country (Figure 3.1) (MoANR 2010).

Following the successful agrarian changes linked with rice in the Fogera Plain, the recent expansion of rice production in different regions demonstrates the agroecological suitability of the crop and its overall potential across the country. The National Rice Research and Development Strategy (NRRDS) recognises seven regional rice research and development hubs (Figure 3.2). These are:

1) Fogera Hub: this area includes the west central highlands of Amhara Region mainly covering Achefer, Dembia, Fogera, Gonder, Metema, Takusa and Zuria districts as main niches.

2) Pawi Hub: this is an area covering northwest lowland areas of Amhara and Benshangul Gumuz Regions - mainly Dangur, Jawi and Pawi districts.

3) Abobo Hub: this covers niche areas in Gameblla regional state - mainly Abobo and Etang districts.

4) Gura Fereda Hub: this covers rice-produc- ing areas in the south and southwest lowlands of Nationalities, Southern Nations, and Peoples' Region - primarily Beralee, Gura Ferda, Menit, Omorate and Weyito districts.

5) May Tsebri Hub: this covers the rice-producing area in the northwest part of Tigray Region.

6) Gode Hub: this covers the southern part of Somali Region - mainly those areas engaged in irrigated rice.

7) Chewaka Hub: this is one of the major rice-producing areas covering the south west highlands of Oromia Region which include East and West Wellega, Illuababora and Jimma Zones.

\subsection{Compatibility of rice in the local farming systems and food recipes}

Following its introduction across different parts of the country in the 1970s and 1980s, rice has been integrated into existing farming systems and incorporated into both local diets and the preparation of traditional foods. The adaptability of the crop has created opportunities for it to be grown in flood-prone

Figure 3.2 Distribution of the national rice hubs in Ethiopia, 2018

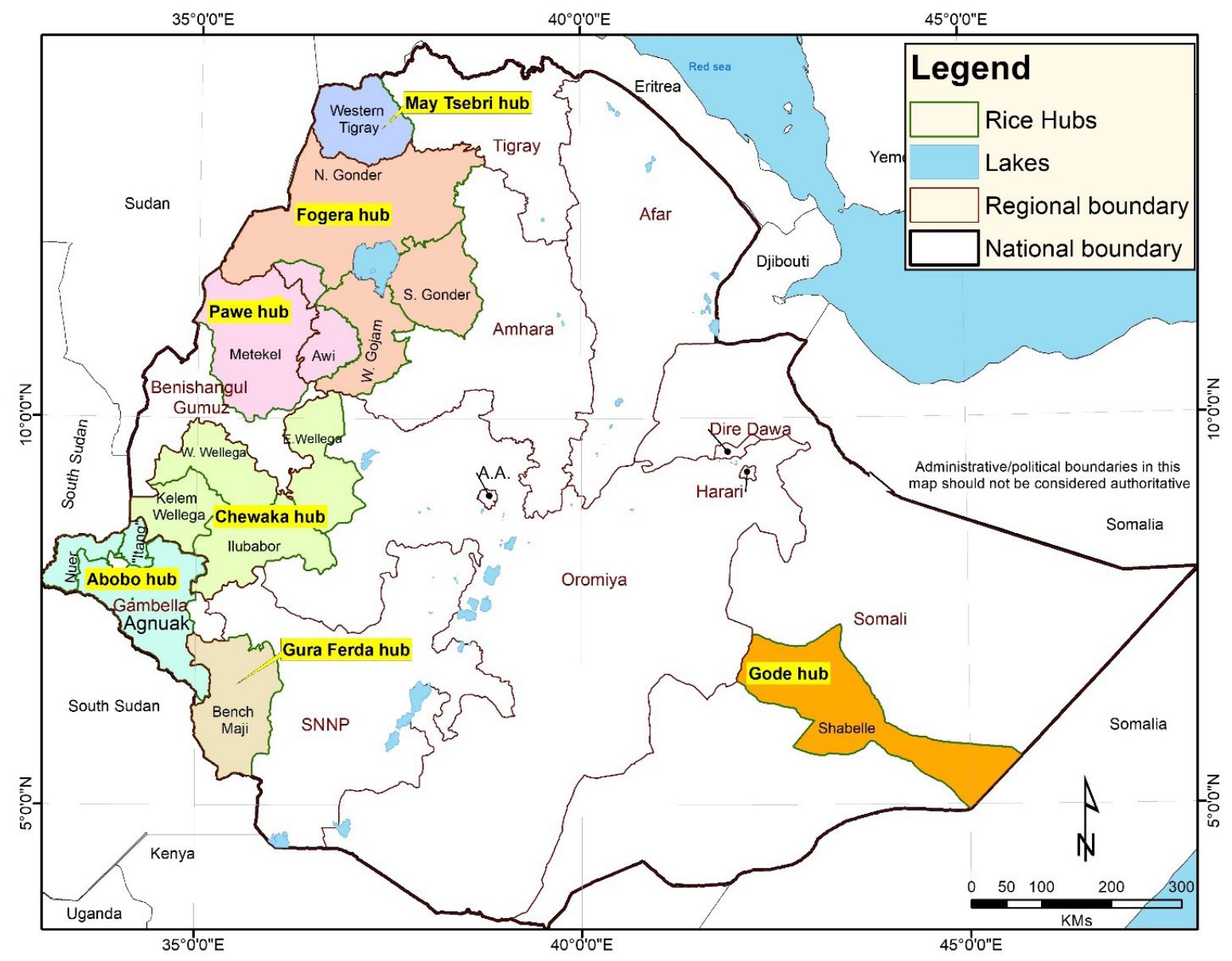

Source: Authors' own 
lowland areas once deemed to be of low agronomic potential. Rice production has also expanded to upland areas, where it has been integrated into rain-fed production systems. Considering the Fogera Plain as an example, rice has brought with it two distinct farming system dynamics, which are related to dynamisms in the wetland and upland areas.

\section{a. Rice and farming system dynamics in the lowlands of the Fogera Plain}

The waterlogged Vertisols of the lowland areas of the Fogera Plain is where rice was first introduced in the 1970s and 80s. Before then, land use was dominated by extensive grazing of the indigenous Fogera cattle breed, which has a large frame, copes well with waterlogged conditions and is one of the best native milk cows in Ethiopia. The area used to be largely characterised by regular flooding during the rainy season - leading to swampy conditions for about a quarter of the year, after which it was devoted almost exclusively to grazing.

The identification of wild rice in the wetlands of the Fogera Plain and the subsequent introduction of a cultivated rice variety shifted the dominant land use activity from cattle grazing to rice production. As rice cultivation expanded, the land used for grazing of the Fogera cattle and production of other crops began to shrink, resulting in significant changes to local farming systems.

As rice has grown in importance within the farming system, there has been a significant decline in the production of chickpea, oats, Niger seed and wheat in the wetlands. The production of Niger seed in the wetlands ended towards the end of 1990s. Teff production also declined dramatically but still exists in pockets, given the traditional attachment to the crop and the relatively high price it still fetches in local markets. There was also the emergence of new crops such as vegetables (onions, tomatoes, etc.) and maize in the wetlands, which are associated with the expansion of channel irrigation in these areas. Grass pea (Lathyrus sativus), a legume grown for human consumption, animal feed and improving soil fertility, is also becoming a more prominent crop with the adoption of a rice-grass pea relay cropping system. It is one of the preferred legume seeds in low fertility soils and arid areas because of its outstanding tolerance of dry or flooding conditions.

As farmers' income from rice increased, they began to invest mainly in supplementary irrigation for rice production. This, in turn, created the opportunity for production of other crops under irrigation, which has further enhanced household incomes. Some farmers were able to invest in deep wells and install motor pumps on their land. The Office of Agriculture has also played an important role in the promotion of householdlevel investment in irrigation systems. Investments in irrigation were prioritised under the second Growth and Transformation Program, the government of Ethiopia's five-year economic development plan, and comprised the largest share (over one-third) of the total budget of US\$582 million of the Ministry of Agriculture's Agricultural Growth Program (World Bank 2015). Irrigation plans give priority to high-value horticultural crops (although rice and lowland wheat also feature) so that farmers can maximise their returns on investment. The aim is to expand coverage of small-scale irrigation schemes from an estimated 2.3 million ha to 4.1 million ha and to expand medium- and large-scale schemes from approximately 658,000 ha to 954,000 ha over the same period (FDRE 2016).

Normally, farmers use irrigation to supplement rainfed rice production as well as for onions, maize and tomatoes, which is often undertaken after harvesting of rice and grass pea. These have provided more opportunities for farmers to diversify and generate supplementary incomes.

\section{b. Farming system dynamism in the uplands of Fogera Plain}

Rice production in the uplands is a relatively recent phenomenon and only began in 2006, following the national research system's introduction of upland rice varieties (before this there were four upland rice varieties) (MoANR 2016). This followed the observed benefits of rice production by farmers in the wetland areas of the Fogera Plain, which encouraged producers in the rain-fed uplands to experiment with the new crop. Prior to the introduction of rice, the upland areas were characterised by mixed crop-livestock farming systems in which diverse types of crops are produced. With the expansion of rice in the upland parts of Fogera, the following trends were observed:

- There has been a significant decline in the production of teff and sorghum from cereals, Niger seed from oil crops and lentil from pulses, due to the shift in land allocation to rice. Farmers reported that this was due to the relatively high economic returns rice provides per unit area versus these other crops.

- There has been a relative increase in the production of chickpea, finger millet, grass pea and maize as well as common beans, which followed the expansion of rice, as was observed in the lowlands. Farmers reported that these crops are good 'successor' crops after rice; allowing them to adopt doublecropping practices. 
- At the same time, there has been a marked decline in livestock production in the uplands of Fogera Plain. The rapid expansion of rice - linked with the expansion in overall crop production associated with population pressure - has reduced grazing land and led to a decline in the importance of livestock in the area.

In addition to the compatibility of rice in these farming systems, the crop has found its way into local diets because it is viewed as compatible with traditional food and drink-making. Observations indicate that in many parts of the country (especially in areas where rice is produced), injera (traditional flat bread) is now made by mixing a small amount of rice flour with teff flour (a ratio of about one to five). This blending is favoured by consumers due to their growing preference for the lighter coloured injera that rice provides. It also reduces the unit cost of injera making, as flour made from rice is often less expensive than that made from teff. During the earlier period, there was a growing trend to make traditional drinks such as tela (black beer) and areki (liquor) from rice but due to increasing demand for rice, farmers are now using maize to prepare these alcoholic beverages and selling rice in domestic food markets to take advantage of rising prices.

\subsection{The economic incentives of rice production}

The economic incentives that rice production provides to farmers emanate from factors such as the productivity levels versus traditional crops such as teff, the growing demand for rice in domestic markets and the relatively high unit price it fetches compared to other cereals. In addition, rice provides the possibility of production on fields once defined as 'wasteland' (due to their waterlogged state during the main growing season). The diverse by-products of rice (straw, bran and husk) have additional economic benefits and are used in animal feed and as fuel.

\subsection{Rice imports and the burden on foreign currency}

Ethiopia has experienced rapid economic growth over the last decade. This transformation has been driven by government investments in agriculture, infrastructure and rural services; leading to substantial increases in cereal yields (FDRE 2016). The country remains dependent on the export of selected agricultural commodities; mainly coffee (US\$836 million), oil seeds (sesame) (US\$363 million), dried legumes (US\$109 million), sheep and goat meat (US\$95 million) and, in recent years, cut flowers (US\$232 million) (in 2018 dollars, OEC 2020). Recent trends also show that the export of industrial products is growing steadily, though their contribution remains modest. All imports require foreign currency generated from the export of this limited range of commodities. In this regard, the government has provided different types of export incentives; including incentives to enhance domestic production of imported commodities such as fibre crops, oil crops and rice. Rice imports have increased substantially in the last decade, reaching just over 300,000 t and costing the country close to US\$200 million in 2018. In addition, a substantial amount of the imported product is low-grade broken rice (mainly from India), which is used in flour production and represents about 20 per cent of the total value of imported rice. ${ }^{1}$

\subsection{Public policy environment and support of development partners}

In 2007, the federal government declared rice a 'millennium crop' in recognition of its productivity and its potential to contribute to food security in the country (MoANR 2010). Since then, a number of rice-specific public and private measures have been put in place. The first and most important were the developments of the NRRDS in 2010 and the Rice Seed Sector Development Strategy (RSSDS) in 2017, which together have played a crucial role in guiding public policy on rice (Alemu 2018; MoANR 2010).

The NRRDS defined and guided national rice research and development (R\&D) efforts at federal and regional level, including (i) the governance of the implementation of the strategy, (ii) identification of priority investment areas and (iii) the setting of targets to ensure selfsufficiency and for later-stage rice export.

The implementations of the NRRDS and later the RSSDS are coordinated by a National Steering Committee (NSC) supported by a National Technical Committee (NTC). The NSC is chaired by the State Minister of Agriculture and the members were drawn from both federal and regional bureaus of agriculture, research institutes, private actors and development partners. To facilitate the smooth operation of the steering committee, a National Rice R\&D Secretariat was established within the Ministry of Agriculture in 2010. The Secretariat has been managed by a policy advisor to the Ministry assigned by the Japan International Cooperation Agency (JICA).

The NTC is comprised of experts from federal organisations, including the Ethiopian Institute of Agricultural Research (EIAR), the Ministry of Agriculture 
and Natural Resources (MoANR), the Agricultural Transformation Agency (ATA), the Agricultural Economics Society of Ethiopia and a number of key development partners including JICA, SG-2000 (Sasakawa-Global 2000) and Mennonite Economic Development Associates (MEDA). At regional level, the rice focal persons are assigned by their respective Bureaus of Agriculture to link the works of the NSC and NTC with the regions. Although this arrangement has been in place since 2010, its effectiveness is reported to vary considerably depending on the attention the specific State Minister at federal level or the focal person at regional level pays to the rice sector at the given time. This implies the need to further institutionalise the organisational setup with well-defined roles and responsibilities in order to ensure commitment and accountability.

The Fogera case - and the recognition that the country needs to become more self-sufficient in domestic rice production - has led the government of Ethiopia to establish a National Rice Stakeholder Platform in 2020 to guide policy and investment. The objective of the platform is to (i) strengthen coordination and advocacy for rice sector development, (ii) facilitate the provision of policy, managerial and technical advisory services for increasing domestic rice production, (iii) support public-private partnerships (PPPs) for mobilising new resources and increasing investments in rice and (iv) serve as a forum for stakeholder networking along the rice value chain. Whether the platform can translate lessons from the Fogera Plain into larger-scale impacts in Ethiopia's other rice-growing regions remains to be seen, but it is clearly an attempt to improve coordination of key rice sector actors at national level.

The support of key development partners has also been critical to the success of these growing policy commitments. Among other things, Ethiopia gained formal membership in CARD, a continental platform supported by JICA which aimed to double rice production in SSA between 2000 and 2018 (since 2010) and in AfricaRice, a pan-African intergovernmental association and a member of CGIAR, a global research partnership for a food secure future, since 2016. Through AfricaRice, the country has also established linkages with another member of CGIAR - the Africa Regional Office of IRRI. These initiatives have increased the country's connections to new ideas, information and innovations for enhancing rice R\&D and helped reinforce national policy commitments to rice sector development, which are described further in Section 5 below. 


\section{TRENDS IN RICE PRODUCTION, IMPORTS AND DOMESTIC CONSUMPTION}

\subsection{Trends in domestic rice production}

The area under domestic rice production has increased significantly over the past decade. This growth can be linked with area expansion as well as productivity gains. Production has expanded from the lowland areas of the Fogera Plain to upland and irrigated areas with the introduction of suitable rice varieties for these agro-ecologies. In collaboration with AfricaRice and IRRI, the national research system has released 35 improved rice varieties 20 for rain-fed upland, 10 for rain-fed lowland, and seven for irrigated rice ecosystems (MoANR, 2018). The limited distribution of these new varieties has contributed to modest but important productivity gains, with the national average increasing from 1.6t/ha in 2001 to 2.8t/ha in 2018; a rise of nearly 43 per cent and a growth rate of well over 2 per cent per year (Alemu 2019; Dessie et al. 2019). According to data from the Central Statistics Agency (CSA), average national rice production increased from 71,320t in 2008 to 171,8500t in 2019 (Figure 4.1). This is significant, but still not sufficient to keep pace with growing demand.

\subsection{Trends in rice imports}

Rice imports to Ethiopia have increased substantially in recent years (Figure 4.1). According to the data from Ethiopian Revenue and Customs Authority (ERCA), ${ }^{2}$ rice imports grew from 22,500t in 2008 to 533,620t in 2019. This saw an increase in foreign currency payments of US\$12.07 million in 2008 to around US\$186.2 million in 2019.

There are four main types of rice imported into the country; all of which are recognised by the Ministry of Trade and ERCA. These are (i) broken rice (unpolished rice which has been milled to remove the hull from the kernel while retaining the rice bran layer and the germ), (ii) husked brown rice (a rice that has only the husk

Figure 4.1 Trends in rice production, imports, consumption and level of self-sufficiency (2008-2019)

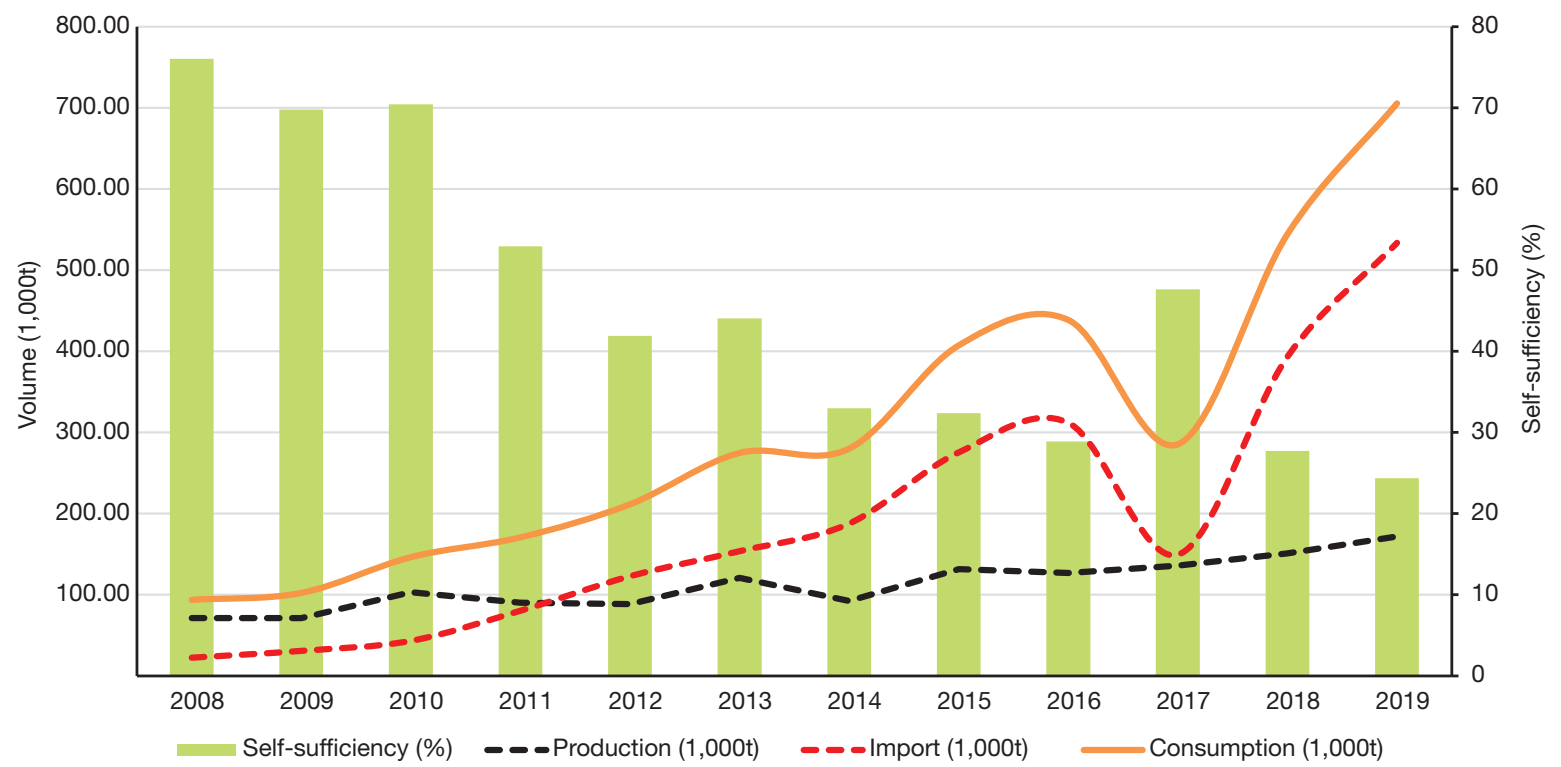

Source: based on data from CSA and Ethiopian Ministry of Revenue (2008-2019) 
removed), (iii) rice in the husk (paddy or rough with husk) and (iv) semi-milled or wholly milled rice. These are further categorised into two major types: Japonica type and Basmati type.

The ERCA import data indicates that the major riceexporting countries to Ethiopia are China, India, Indonesia, Pakistan, Sri Lanka, Thailand and the United Arab Emirates. When compared to other countries, India accounts for the lion's share of all rice imported in Ethiopia with, on average, about 50 per cent of the total. $^{3}$

\subsection{Trends in domestic consumption and self-sufficiency}

Considering domestic consumption as the sum of domestic production and imports, the total consumption of rice in Ethiopia has grown considerably. This is in line with the trend in consumption observed in all African countries (Van Oort 2015; Seck et al. 2013; Wopereis et al. 2013). The trends in domestic production and imports indicate that the rate of increase was considerably higher for rice imports compared to domestic production - which shows considerable decline in the rate of rice consumption self-sufficiency. The estimated rate indicates that rice self-sufficiency in Ethiopia has decreased from about 76 per cent in 2008 to 24 per cent in 2019 (Figure 4.1).

The trends in rice imports reflect the increased demand for rice in the country and help to stabilise the domestic grain markets. However, they also raise several important policy implications. These are:

1) Increasing reliance on rice imports will have a negative impact on the national rice sector as it is at an early stage both in terms of research and development; making local rice less competitive than imports in domestic markets and placing additional burden on the meagre foreign currency reserves.

2) The increased importation of broken rice reduces the incentive for domestic producers because competitiveness related to quality improvement will be low.

3) There are no formal regulatory measures in place to assess the quality of the imported broken rice and its suitability for human consumption. The main use of the imported broken rice is for preparation of injera by mixing with teff, but some specialists have raised concerns.
4) There is inadequate information on whether the imported rice is purchased at competitive world market prices or below market 'dumping' prices by exporting countries, particularly for low-quality broken rice. 


\section{TRENDS IN RICE RESEARCH AND DEVELOPMENT}

Given the relatively recent introduction of rice to the country and associated gaps in rice R\&D, a priority intervention identified by NRRDS was the establishment of a National Center of Excellence for Rice Research and Capacity Building (NCERR) at Fogera in 2013 as one of the 17 official research centres of the EIAR (Tadesse et al. 2019). Supported by EthioRice - a joint initiative of the governments of Ethiopia and Japan (2015-2020), the NCERR was designed to create a well-organised, national rice research programme through facilitation of the development, accumulation and sharing of innovations in rice production, processing and storage, the building of the capacities of Ethiopian scientists to undertake applied rice research, provision of training to farmers and others in the rice value chain and establishment of a system of rice-related information sharing among all relevant stakeholders (Alemu 2019).

In parallel with these efforts, the country has been engaged with international initiatives to ensure the transfer of knowledge and skills for effective rice R\&D. The memberships of Ethiopia in the JICA-supported CARD and in AfricaRice of CGIAR have been of critical importance. Ethiopia's engagement in CARD has allowed the country to share rice $R \& D$ experiences from other African countries and gain access to relevant capacity-development opportunities, especially in shortterm training programmes for rice researchers and extension workers. Membership with AfricaRice has created international linkages for germplasm exchange, including cooperation with IRRI (as described in Section 4.1), as well as short and long-term training opportunities.

Several development partners have also shown interest in support of the development of the rice sector in Ethiopia. The three most important over the past decade are (i) EthioRice, funded by JICA, (ii) MEDA, supported by Global Affairs Canada, and (iii) Agro-business induced growth (AgroBIG), funded by the Finnish International Development Agency.

The EthioRice project, the first phase of which ran from 2015-2020, supported the establishment of the National Rice Research and Training Center (NRRTC) in Fogera (Tadesse et al. 2019). The NRRTC, which was officially opened in 2018, was designed to create a well-organised national rice research programme through facilitation of the development, accumulation, and sharing of innovations in rice production, processing and storage, the building of the capacities of Ethiopian scientists to undertake applied rice research, provision of training to farmers and others in the rice value chain, and establishment of a system of rice-related information sharing among all relevant stakeholders (Alemu 2019). Recently, the Japanese and Ethiopian governments started preparing a second phase of EthioRice aimed at strengthening and extending these activities to 2025 .

The EDGET Project (Ethiopians Driving Growth through Entrepreneurship and Trade) of the MEDA also supported rice-related activities (2010-2015) with financial assistance from the government of Canada. These sought to improve (i) rice input supplies, awareness about improved techniques and irrigation, including efficient micro-irrigation technologies and rural credit, (ii) rice post-harvest handling related to storage, grading and market segmentation as well as improved technologies for value-addition activities and (iii) rice market linkages through consolidation/bulking and other strategies to deal more effectively with traders and development of strategies for selling into new markets. A second phase (2016-2020) of MEDA's rice project called EMERTA (Ethiopians Motivating Enterprises to Rise in Trade and Agri-business) targets promotion of agribusinesses with a motto of 'creating business solutions to poverty'. It focuses on rice (as well as the gemstone and vegetable sectors) with the objective of increasing employment and income for women and men in Amhara region.

AgroBIG ${ }^{4}$ was implemented as a bilateral cooperation programme of the governments of Ethiopia and Finland (2013-2017). It aimed to scale up successes of the first phase of the programme in promoting business-induced growth by working closely with smallholder farmers, agricultural cooperatives, private actors and other value chain actors with particular emphasis on youth and women. A second phase of AgroBIG (2018-2021) targets rice value chain development in the eight districts around Lake Tana in Amhara Region; including the main riceproducing districts of Fogera, Libokemkem and Dera in the Fogera Plain. 


\section{KEY CHALLENGES FACING THE RICE SECTOR}

Ethiopia faces a number of major challenges that are constraining the development of its rice sector. The 2010 NRRDS (MoANR 2010) and the 2017 RSSDS (MoANR 2017) have clearly identified several issues that require attention:

\section{a. Poor performance of the rice seed sector and other inputs}

The contribution of the formal seed sector in rice is very limited and, in general, the supply of certified rice seed is limited to few farmers' cooperative unions with almost no participation of private actors. The overall institutional coordination and alignment of rice seed-related interventions among EIAR, the Regional Agricultural Research Institutes, MoANR's extension services, Regional Bureaus of Agriculture and the ATA, remains weak (MoANR 2017). This has prevented widespread distribution of the improved rice varieties already released by EIAR which has, in turn, resulted in the continuing reliance on rice farmers' own poorquality seed.

\section{b. Limited contribution of large-scale commercial rice production despite a special incentive for access to land}

A number of large-scale commercial farms have received licenses to engage in rice production, mainly led by foreign investors. The Land Matrix Initiative records a total of ten such deals focusing on rice (LMI 2020). Two of the largest concessions have gone to Karuturi Global Ltd of India and Saudi-Star, both of which were allotted 300,000ha of land in the Gambella Region. However, only Saudi-Star has thus far managed to make land operational for rice production with about 5,000 ha in 2018. Saudi-Star is also the first commercial farm to set up a modern large-scale processing facility at Bisheftu town in Oromia Region. These foreign ventures are controversial and have been called 'land grabs' by some analysts (Miru 2019; Vhughen and Gebru 2013). Furthermore, the companies have been labelled as 'poor performers' for their failure to achieve agreed investment targets or follow practices that meet internationally-accepted environmental, social and economic standards (Persson 2019). Consequently, the contribution of these large-scale commercial operations to increasing rice production or improving livelihoods remains small. The key challenges - among others - are (i) the limited commitment of investors given the other opportunities available linked with the investment incentives, such as use of the accessed loan for other lucrative investments, (ii) the prevailing unrest and social insecurity in the different investment areas, (iii) the limited follow-up by public organisations to address emerging challenges in a timely manner and (iv) the general lack of skills and knowledge in managing commercial farms (and rice production in particular).

\section{c. Competition of imported rice with local production on both quality and quantity}

Though there have been attempts to get the domestic rice to the supermarkets in large cities such as Bahir Dar and Addis Ababa, challenges persist; mainly with regard to quality and the sustainability of the paddy supply, as well as the under-performance of local processing and packing companies. Most of the domestic rice is marketed and utilised in the local markets within the major rice-producing niches. In general, in the main urban market centres, imported rice of different types including broken rice used in flour production for injera - are preferred by most consumers. The main reasons identified are related to (i) the poor quality of the rice in terms of grain size, maturity and purity, (ii) a lack of awareness and application of improved pre-harvest and production management practices by farmers, (iii) shortages of improved post-harvest mechanisation for processing, and inadequate awareness of post-harvest management and handling and (iv) the huge demand for broken imported rice which is sold below world market prices and therefore often trumps domestic rice on price as well as quality.

\section{d. Lack of skilled human resources and research facilities for improving rice productivity and production}

As rice is a relatively recent introduction in most parts of the country, there is only limited knowledge and capacity among most value chain actors to improve its production, processing and marketing. The research facilities and human resources needed to intensify and expand production of improved varieties are still in developmental stages. Expertise in rice 
extension remains weak in most regions. The skills and knowledge in rice processing and value addition have grown largely through trial and error with minimal external assistance. The limited skills and knowledge in R\&D in the areas of rice mechanisation and irrigation present even greater challenges. For this reason, the establishing of the NRRTC at Fogera represents a major commitment to improving R\&D capacities.

It is in recognition of these skills and knowledge gaps that the NRRTC has been given the mandate for the timely provision of required services and products. However, the NRRTC still needs to be equipped with (i) the required training facilities, (ii) pre-harvest and postharvest rice-processing technologies for demonstration and promotion, (iii) training curricula relevant to different stakeholders (smallholder farmers, commercial farms, processors, extension agents and researchers) and (iv) financial resources and institutional mechanisms to ensure the long-term provision of training support and services. The recent announcement of the second phase of EthioRice, which will run to 2025, will help ensure the NRRTC's mandate is achieved.

\section{e. Inadequate infrastructure for commercialisation of rice production}

The commercialisation of domestic rice is hindered mainly due to the lack of proper technological options in rice processing. Most processing is done by smallscale, independent processors with only modest working capital and limited machinery and facilities. There have been a number of attempts to introduce better rice-processing technologies and practices, and a small emerging group of specialist importers attempting to bring in improved rice-processing parts and machinery. However, there are still no local manufacturers who can supply good-quality, reasonably-priced technologies. Consequently, much of the rice produced domestically is broken during the milling process and therefore goes into flour-making, where it is mixed with teff for injera.

Some private entrepreneurs are now sourcing new processing technology from as far away as China. However, it is likely this will have only a modest impact on processing capacity in the short term. Therefore, a more long-term, strategic solution is needed to improve the local manufacturing of milling machinery and equipment while selectively importing appropriate technology for use by small-scale operators.

\section{f. Poor marketing system for domestic production compared to imported rice}

Traditional rice value chains in Ethiopia are made up of farmers, processors and traders who have little capital, manage small quantities of products and supply rice of varying quality. These chains dominate local supplies because of the uncertain and restrictive contexts in which they operate. Therefore, upgrading local value chains is a real challenge in terms of vertical coordination, technology, finance and policies.

The current domestic rice marketing system is rather fragmented and underdeveloped. It is mainly facilitated by small-scale processors who often serve as the main buyers and wholesalers in each of the regional rice hubs. At the same time, imported rice - both highquality polished rice and lower-quality broken rice has a well-established distribution system that reaches most major urban centres and many rural areas.

The current marketing system for domestic rice disadvantages small-scale producers, as many processors/tradersareknowntogivethem unfavourable terms of trade. This includes (i) manipulating weights and measures to record lower amounts for farmers' produce, (ii) deliberately increasing the extent of rice grain breakages to ensure a reduced sale price due to lower quality and (iii) offering 'free' or low-priced processing services in return for retaining the broken rice and husks. In interviews, farmers frequently complained about these practices but felt they were unable to change these arrangements to something they might view as fairer and more mutually beneficial. As domestic rice production expands, it will be important to develop better systems for upgrading and increasing value addition while improving market information monitoring systems to boost the bargaining power of smallholder rice producers.

\section{g. The impact of COVID-19 on the rice system}

The recent COVID-19 pandemic has presented a new challenge to the development of the rice sector in Ethiopia, with value chains disrupted across the country, and Africa as a whole. During the first half of 2020, rice supply chains were stretched; production, transportation and consumption fell sharply and household incomes were affected (FAO 2020a; FAO 2020b; FAO 2020c; FAO 2020d). Several of the major Asian rice exporting countries - including Thailand and Vietnam - responded to the crisis by closing frontiers and imposing temporary trade restrictions, which resulted in an increase in world rice prices. Furthermore, rice futures rose to US\$18/CWT; an increase of over 50 per cent in one year and a level not seen since 2011 (Fontan Sers and Mughal 2020).

These recent price movements suggest that international market prices will continue to be more volatile and move upwards; at least until the pandemic is resolved. With the demand for public distribution 
Figure 6.1 Expected vulnerability of CARD member countries during COVID-19 pandemic

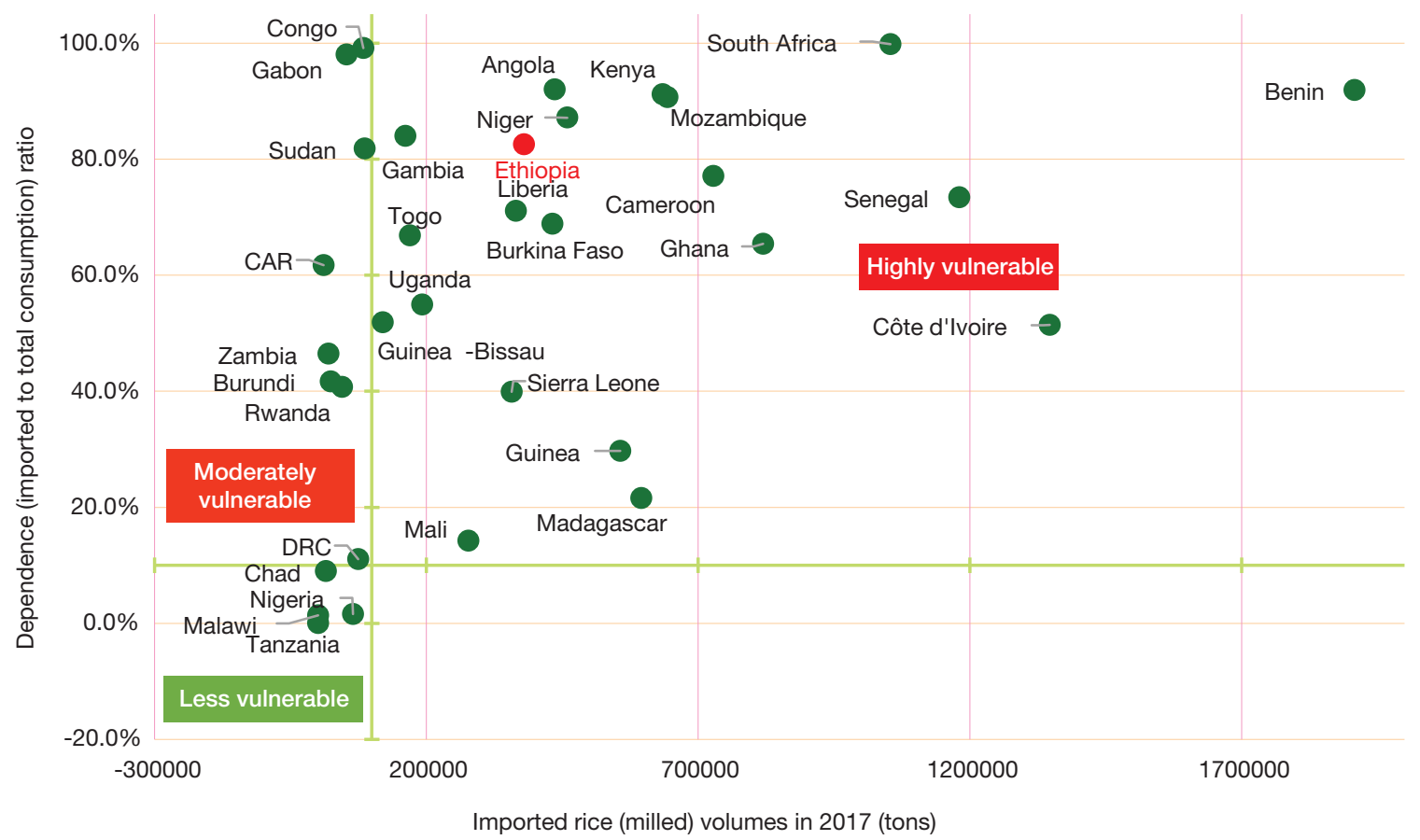

Source: CARD 2020.

set to rise for the duration of the COVID-19 pandemic, any such excessive stock-piling and/or export controls by major Asian rice-exporting countries are likely to continue to disrupt the price equilibrium in African markets (CARD 2020; Fontan Sers and Mughal 2020). The extent of vulnerability of African nations to the COVID-19 crisis relates in part to their rice importdependence ratio (the share of imported rice over the total demand in the given country) and the volume of importation (van Oort et al. 2015). Available data on imports and production (milled equivalent) of rice in 2017 for which complete datasets are available (Figure 6.1) reveal that Ethiopia has an import-dependence ratio of nearly 80 per cent (CARD 2020). It is therefore highly prone to shortages in external supplies and/or restricted rice trade flows.

The situation could be exacerbated further if world market rice prices remain volatile and subject to speculation. This price shock and supply squeeze threatens to further aggravate an already fragile food security situation in the country and highlights the need for greater efforts to improve national rice selfsufficiency. However, with its growing population, changing consumer preferences and modest productivity increases, Ethiopia is unlikely to become fully self-sufficient in the short- to medium-term. This implies that for the foreseeable future, a mixture of area expansion and reliance on imports will be needed on top of yield gap closure. Further research is needed for the identification of the most suitable new land for rice area expansion and areas that should be protected.

It is important to stress that the policies governing rice trading and marketing in Africa are increasingly integrated through regional economic commissions. Hence, any policy actions to promote rice selfsufficiency at national level will need to be aligned with relevant regional policy frameworks, including those established under the Common Market for Eastern and Southern Africa. Any consequences (intended or unintended) of their policy actions will need to be assessed in the context of the expected outcomes of individual member countries, including Ethiopia.

With the outbreak of the COVID-19 crisis, there have been moderate changes in the operation of the rice value chain in Ethiopia through the different responses by the value chain actors to the measures put in place by the government. The key preventive measures and restrictions relevant to the rice value chain are (i) mobility restriction and increased cost of transportation for both humans and goods, (ii) establishment of command posts (task forces) at different administration levels for follow up and control of movement of goods and pricing as per directives, and (iii) reduced extent of public services associated with rice production, processing and marketing. With COVID-19 impacts emerging after 
the harvest of the 2018/19 rice production season, farmers have not been greatly affected in their riceproduction processes. Instead, they are enjoying higher prices with an average monthly increase of 5.67 per cent from January to May 2020; a 14.72 per cent rise on the 2019 five-month average price. However, collectors and farmer-traders have been seriously affected and forced out of the market as smallholder farmers' market supply has decreased considerably amid expectations of better prices in the coming months. The response of rice processors to the COVID-19 pandemic is related to the change of strategy in providing processing and marketing services where, currently, rice processors have limited their processing service provision and are engaged in the purchase of paddy and storing paddy rice in private storehouses.

Ethiopia imports both semi-milled and wholly-milled rice as well as broken rice; mainly from India and Pakistan and, to a lesser extent, Vietnam. However, these countries have recently put in place a full export ban of rice in an effort to contain the impact of the pandemic. Ethiopian importers are shipping only purchased and/ or signed contracts of export. Accordingly, the volume of import from January to March 2020 was more or less the same as the volume of import in the corresponding months of 2019. Recognising the strategic importance of rice and the expected challenges presented by the COVID-19 pandemic, the Ministry of Agriculture has designed intervention options to boost domestic production and productivity; including expansion of rice production in the lowlands of the country, where there is huge potential for irrigated agriculture. 
This paper outlined the increasing importance of rice as a strategic crop in Ethiopia. It outlined the main challenges facing rice sector development, including the poor performance of the rice seed sector, the limited contribution of large-scale commercial rice production, competition for imported rice with local production both in terms of quality and quantity, the lack of skilled human resources and research facilities, the inadequate infrastructure for improving rice production, the underdeveloped state of the domestic marketing system and, most recently, the impact of the COVID-19 crisis on the system.

While the country is endowed with huge potential for both rain-fed and irrigated rice production, rapidlyincreasing consumer demand and low levels of domestic production mean that the national rice self-sufficiency level stood at only approximately 24 per cent in 2019. This means that three-quarters of Ethiopia's rice requirements will have to be met through imports, which creates a major drain on the country's meagre foreign reserves and exposes it to vagaries of international markets.

To begin to shift the balance more in favour of Ethiopia's long-term interests, policy makers will need to decide whether to aim to increase or decrease the country's dependency on imports. If they consider domestic production to be unacceptably low or the projected future rice import-dependence ratio unacceptably high, then a combination of intensification to improve yield levels and area expansion to increase coverage will be needed (Tadesse et al. 2019; van Oort 2015; Seck 2013). Further attention will also need to be paid to the rest of the rice value chain in order to improve the quality and consistency of supply to consumers and allow domestic rice to compete with imports.

In particular, the following issues will need to be addressed:

- Greater investment in domestic rice research and development capacity to improve the overall competitiveness of the sector.

- Making the most of memberships with CARD, AfricaRice and IRRI to gain access to new technologies, partnerships and knowledge exchange.

- Strategically selecting appropriate technologies and practices from other rice-producing countries in Africa and Asia and adapting them to Ethiopian conditions.

- Strategising the training and outreach activities of NRRTC to strengthen the capacity to all value chain actors and members of the national rice system.

- Enhancing rice processing and value addition by providing formal training for the operation and maintenance of rice-processing facilities.

- Standardising the key requirements for licensing rice mills and incentivising processors' fulfilment of quality standard requirements through investment in key facilities.

- Providing farmers with fair terms of trade and promoting an improved paddy and milled-rice marketing system.

- Verifying the safety and regularity of imported broken rice to ensure it is fit for human consumption and sold at fair market prices.

- Clarifying the roles and responsibilities of the NSC and the NTC at national level and the focal persons at regional level to improve their functions and performance.

- Supporting the new National Rice Stakeholder Platform to strengthen coordination and advocacy for rice sector development, facilitate the provision of policy, managerial and technical advisory services for increasing domestic rice production and improving PPPs to increase investments in rice.

- Recognising that systemic shocks such as COVID-19 and climate change are likely to disrupt global rice supply chains and increase the volatility of world market prices in future. The country must therefore hedge against this uncertainty by improving domestic productivity and production and improving quality and consistency of supply through enhanced value addition, and strengthened trade relations with regional partners through existing frameworks. 


\section{REFERENCES}

AfricaRice (2018a) Continental Investment Plan for Accelerating Rice Self-Sufficiency in Africa (CiPRiSSA), Abidjan: Africa Rice Center

AfricaRice (2018b) Report of the High-Level Ministerial Conference on Rice: Delivering on Commitments to Transform Africa's Rice Industry. Sphères Ministérielles de Diamniadio, Senegal, 25 September 2018, Abidjan: Africa Rice Center

Alemu, D. et al. (2019) 'Rice Commercialization and Livelihood Pathways of Farmers' in Fogera Plain' in T. Tadesse (eds.) Advances in Rice Research and Development in Ethiopia, Addis Ababa: Ethiopian Institute of Agricultural Research

Alemu, D. et al. (2018) A Historical Analysis of Rice Commericalisation in Ethiopia: The Case of the Fogera Plain, APRA Working Paper 18, Brighton: Future Agricultures Consortium

CARD (2020) Potential Impacts of COVID-19 on Rice Production and Supply in Africa and Policy Options, A Policy Note to CARD Stakeholders (May 2020), Nairobi: Coalition for African Rice Development

Dessie, A.; Worede, F., Atnaf, M., Tadesse, B. and Mengistu, G. (2019) 'Rice Genetic Improvement for Different Ecosystems in Ethiopia' in T. Tadesse et al. (eds.), Advances in Rice Research and Development in Ethiopia, Addis Ababa: Ethiopian Institute of Agricultural Research

Erkossa, T.; Haileslassie, A. and MacAlister, C. (2014) 'Enhancing Farming System Water Productivity Through Alternative Land Use and Water Management in Vertisol Areas of Ethiopian Blue Nile Basin (Abay)', Agricultural Water Management, 132: 120-128

FDRE (2016) Growth and Transformation Plan II (GTP II) (2015/16-2019/20) (Vol. I), Addis Ababa: Federal Democratic Republic of Ethiopia

FAO (2020a) COVID-19 and the Risk to Food Supply Chains: How to Respond?, Rome: Food and Agriculture Organization of the United Nations

FAO (2020b) COVID-19 Global Economic Recession: Avoiding Hunger Must Be at the Centre of the Economic Stimulus, Rome: Food and Agriculture Organization of the United Nations

FAO (2020c) Impact of COVID-19 on Informal Workers, Rome: Food and Agriculture Organization of the United Nations

FAO (2020d) Sustainable Crop Production and COVID-19, Rome: Food and Agriculture Organization of the United Nations

Fonten-Sers, C. and Mughal, M. (2020) 'COVID-19 Outbreak and the Need for Rice Self-Sufficiency in West Africa', World Development, 135 (2020) 105071.

LMI (2020) 'Ethiopia: By Crop' Land Matrix, https://landmatrix.org/data/by-crop/?country=231\&more=40 (accessed 18 August 2020) 
MEDA (2019) MEDA 2019 Annual Report, Waterloo: Mennonite Economic Development Associates (MEDA), https://www.meda.org/annual-report (accessed 18 August 2020)

Miru, O. (2019) 'Ethiopia: Gambellan Solutions to Gambellan Problems', Farmlandgrab.org, 17 April, https:// farmlandgrab.org/28898 (accessed 18 August 2020)

MoANR (2018) Crop Variety Register. Issue No. 21. Plant Variety Release, Protection and Seed Quality Control Directorate, Ministry of Agriculture, Addis Ababa, Ethiopia.

MoANR (2017) Rice Seed Sector Development Strategy, Addis Ababa: Ministry of Agriculture and Natural Resources

MoANR (2010) National Rice Research and Development Strategy, Addis Ababa: Ministry of Agriculture and Natural Resources

OEC (2020) 'Ethiopia', The Observatory of Economic Complexity (OEC), https://oec.world/en/profile/country/eth/ (accessed 14 August 2020)

Persson, A.G.M. (2019) Foreign Direct Investment in Large-Scale Agriculture in Africa: Economic, Social and Environmental Sustainability in Ethiopia, London: Routledge

Seck, P.A.; Touré, A.A., Coulibaly, J., Diagne, A. and Wopereis, M.C.S. (2013) 'Africa's Rice Economy Before and After the 2008 Rice Crisis' in M.C.S. Wopereis et al. (eds.), Realizing Africa's Rice Promise, Wallingford, UK: CAB International

Sheahan, M. and Barrett, C.B. (2017) 'Ten Striking Facts About Agricultural Input Use in Sub-Saharan Africa', Food Policy, 67: 12-25

Tadesse, T.; Atnaf, M., Alemu, D., Tadesse, T. and Shiratori, K. (2019) Advances in Rice Research and Development in Ethiopia, Addis Ababa: Ethiopian Institute of Agricultural Research

Van Oort, P.A.J. et al. (2015) 'Assessment of Rice Self-Sufficiency in 2025 in Eight African Countries', Global Food Security, 5: 39-49

Vhughen, D. and Gebru, A. (2013) Large-Scale Acquisitions of Land in Ethiopia, Focus on Land in Africa Brief, Washington, DC: World Resources Institute and Landesa Rural Development Institute

World Bank (2016) Second Agricultural Growth Project, Ethiopia (P148591). Implementation Status \& Results Report, Washington, DC: World Bank

Wopereis, M.C.S.; Diagne, A., Johnson, D.E. and Seck, P.A. (2013) 'Realizing Africa's Rice Promise: Priorities for Action' in M.C.S. Wopereis et al. (eds.), Realizing Africa's Rice Promise, Wallingford, UK: CAB International 


\section{ENDNOTES}

1 Based on data from the Ethiopian Revenues and Customs Authority, 2018

2 www.erca.gov.et/index.php/

3 www.erca.gov.et/index.php/

4 AgroBIG website - http://agrobig.org/ (accessed 18 August 2020) 
Alemu, D. and Thompson, J. (2020) The Emerging Importance of Rice as a Strategic Crop in Ethiopia, Working Paper 44, Brighton: Future Agricultures Consortium

\section{(cc) BY-NC-ND}

This is an Open Access report distributed under the terms of the Attribution-Non Commercial-No Derivs 4.0 Unported (CC BY-NC-ND 4.0) Attribution - You must give appropriate credit, provide a link to the license, and indicate if changes were made. You may do so in any reasonable manner, but not in any way that suggests the licensor endorses you or your use. NonCommercial — You may not use the material for commercial purposes. NoDerivatives - If you remix, transform, or build upon the material, you may not distribute the modified material. You are free to: Share - copy and redistribute the material in any medium or format.

https://creativecommons.org/licenses/by-nc-nd/4.0/legalcode

If you use the work, we ask that you reference the APRA website (www.future-agricultures.org/apra/) and send a copy of the work or a link to its use online to the following address for our archive: APRA, Future Agricultures Consortium, University of Sussex,

Brighton BN1 9RE, UK (apra@ids.ac.uk)

All APRA Working Papers go through a review process before publication.

\section{Cccreative}

\section{DO YOU HAVE COMMENTS ON THIS PAPER?}

We would welcome your feedback on this working paper!

To provide brief comments, please follow this link to our short APRA Working Paper Feedback form: https://goo.gl/forms/1iVnXhhrlGesfR9

Agricultural Policy Research in Africa (APRA) is a programme of the Future Agricultures Consortium (FAC) which is

generating new evidence and policy-relevant insights on more inclusive pathways to agricultural commercialisation in sub-Saharan Africa. APRA is funded with UK aid from the UK Foreign, Commonwealth \&

Development Office (FCDO) and will run from 2016-2022. 